\title{
Self harm and attempted suicide in adults: 10 practical questions and answers for emergency department staff
}

\author{
A J Mitchell, M Dennis
}

Emerg Med J 2006;23:251-255. doi: 10.1136/emj.2005.027250

Self harm is a complex behaviour that can be best thought of as a maladaptive response to acute and chronic stress, often but not exclusively linked with thoughts of dying. Patients presenting with self harm usually have current psychosocial difficulties, are likely to be suffering from mental health problems, and are at significant risk of further self harm and suicide. Recent guidelines suggest that all self harm attendees should receive an initial risk assessment at triage in the emergency department. A more detailed mental health assessment and an assessment of psychological and social needs should then be performed by trained staff, ideally specialist mental professionals experienced in this area. Risk of subsequent suicide is particularly high in those with high unresolved suicidal intent, depressive disorder, chronic alcohol and drug misuse, social isolation, and current physical illness. Patients with one or more of these risk factors should be offered enhanced care that may include inpatient or outpatient follow up care, a list of local support resources, and, where possible, self help material. Frequent repeaters, those with alcohol and substance use problems, those with physical or mental illness, and those who are isolated also require input from specialist mental health professionals. It is also recommended that adolescents and elderly people warrant a mandatory specialist assessment.

See end of article for authors' affiliations

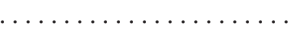

Correspondence to: Dr A J Mitchell

Department of Liaison Psychiatry, Brandon Unit, Leicester General Hospital, Leicester, UK; alex. mitchell@leicspart.nhs.uk

Accepted for publication 16 October 2005 considerably between hospitals. ${ }^{5-7}$ To some extent this may reflect local resources for DSH, but attitudes and experience of local ED staff may also be important. In an attempt to help, two independent sets of national guidelines for the United Kingdom were published in 2004, by the National Institute of Clinical Excellence (NICE) $^{8}$ and the Royal College of Psychiatrists. ${ }^{9}$

Here we present a practical review of recent DSH research, in a question and answer format.

\section{WHY DO I SEEM TO BE SEEING MORE PATIENTS WITH DSH THAN EVER \\ BEFORE?}

In contrast to the trends in completed suicide, there has been a rise in the incidence of self harm in the UK over the past 20 years. ${ }^{1}$ Age specific rates for self harm are shown (fig 1). Two thirds of patients who self harm are $<35$ years old and two thirds of people in this age group are female. Even though self harm in older people is a relatively rare event, the profile more closely resembles completed suicide in that attempts involve a higher degree of intent. ${ }^{10}$ There is particular concern that the rate in young men aged 15-24 years of age is rising more quickly than in any other group. ${ }^{11}$

WHY DO PATIENTS HARM THEMSELVES?

The answer to this question can be viewed from several perspectives, such as the individual's intentions at the time of the act, social precipitants, and mental health reasons. A significant proportion of patients intended to die at the time of the attempt (that is, they made a failed suicide attempt), but this can be difficult to establish if there is a protracted delay prior to the assessment. Most wanted to escape from an intolerable situation or intolerable state of mind, and a sizeable number can offer no clear explanation other than "losing control."12 Only a small minority (13\%) wanted to punish someone or make someone feel guilty. ${ }^{13}$ Intention at the time and current wish to die are risk factors for repetition. ${ }^{14}$

Social circumstances are important; those who are isolated or living in areas of socioeconomic deprivation have increased rates of suicide and DSH (see below). ${ }^{15}$ Evidence also supports an excess of life events, especially in the month before the self harm attempt. ${ }^{16}$ Frequently, the

Abbreviations: DSH, deliberate self harm; ED, emergency department; GP, general practitioner; NICE, National Institute of Clinical Excellence; RCT, randomised controlled trial; SSRI, selective serotonin reuptake inhibitors
It is now well established that services for individuals who present following DSH vary 


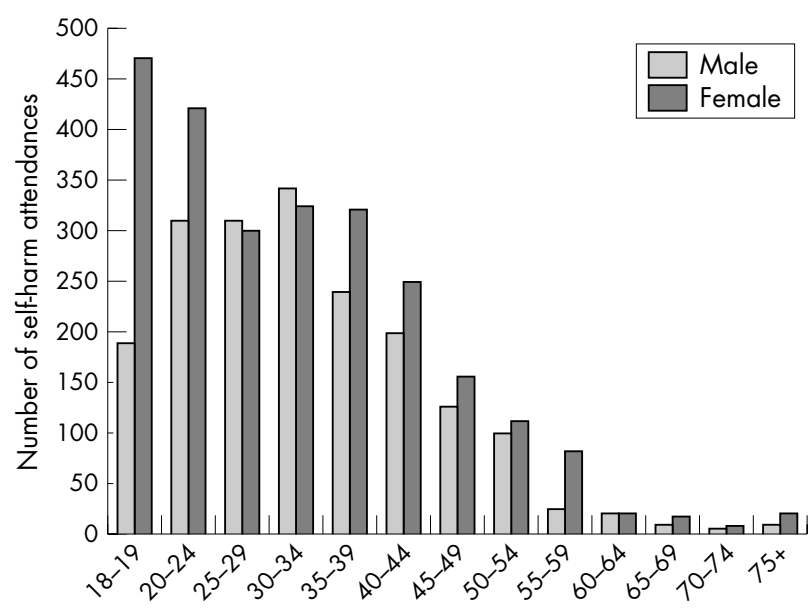

Figure 1 Epidemiology of self harm attendances at the ED in 32 hospitals in england.

type of events experienced by younger people is related to relationship difficulties, but in older people it is more likely to be health or bereavement related. ${ }^{17} 18$ Vulnerability factors such as early loss or separation from one or both parents, childhood abuse, unemployment, and absence of living in a family unit are contributory. ${ }^{19}$ Many patients consider that their problems are insolvable, ${ }^{20}$ and although self harm is an immediate but not long term response, they often cannot think of any other way out of their situation at the time. Mental health difficulties, particularly depression, alcohol or substance misuse, and personality disorder are frequently seen (see below). ${ }^{21} 22$

\section{WHICH GROUP OF HEALTH PROFESSIONALS SHOULD PERFORM THE RISK ASSESSMENT AND OFFER TREATMENT?}

Patients who present to the ED are often seen by several members of staff for short periods in a busy and possibly chaotic environment. This is not conducive to a sensitive assessment of mental health difficulties. Both the NICE guidelines and the Royal College of Psychiatrists believe that an immediate risk assessment be made on the patient's arrival in the department. Where the guidelines are discrepant is regarding who should perform more in depth psychosocial risk assessment. The NICE guidelines suggest that all people who have self harmed should be offered a full mental health and social needs assessment by a mental health professional. ${ }^{8}$ The Royal College guidelines see this as the ideal option, but acknowledge that in the real world, any trained health professional may perform this role. ${ }^{9}$ It is generally accepted that the best option is a dedicated multiprofessional team who have expertise in self harm.

\section{WHAT DOES PSYCHOSOCIAL ASSESSMENT INVOLVE?}

When making an assessment, several of important principles apply. Offer privacy, conduct the interview safely and with adequate time, and let the patient tell their story. There are three main issues to determine in the assessment process:

- Are there current mental health difficulties?

- What is the risk of further self harm or suicide?

- Are there any current medical or social problems (assessment of need)?

Accurate risk assessment is often a very difficult task (see next question), and there are several key areas that need to fully explored. In particular, these include: $(a)$ a careful history of the events surrounding the self harm attempt, concentrating on factors that indicate significant intent; $(b)$ symptoms indicating previous mental health problems (including previous DSH); (c) harmful use of alcohol or illicit drugs; (d) social circumstances and problems (are family sympathetic and can they be recruited to help?, are difficulties likely to improve or worsen after DSH?); and (e) a forensic history and a mental state examination, paying particular attention to symptoms of depression and current suicidal thoughts, plans or intent to self harm again. At the end of the interview, the assessor should plan what action is to be taken collaboratively with the patient.

\section{SHOULD I USE A RISK ASSESSMENT TOOL?}

One advantage of a short screening instrument is that it can act as a prompt that may be useful if referral to mental health services is considered. An example of a commonly used tool in the ED is the SAD PERSONS scale. ${ }^{23}$ Unfortunately, large scale studies examining the accuracy of risk assessments scales are less than impressive: studies involving the Beck Suicide Intent Scale and the Edinburgh Risk of Repetition Scale found low accuracy in predicting self harm and suicide. ${ }^{24}{ }^{25}$ New scales for assessing risk designed for ED are currently under development. ${ }^{26}$

\section{WHAT TREATMENTS ARE AVAILABLE?}

No definitive intervention for DSH has been recommended by the Royal College of Psychiatrists or by NICE, in spite of a reviewing more than 20 randomised controlled trials. ${ }^{89}$ Nevertheless, the following interventions have recently been summarised in Clinical Evidence: ${ }^{27}$

\section{Antidepressants}

Small randomised control trials hint at a possible benefit, but larger scale studies are required to replicate these findings. ${ }^{28}{ }^{29}$ Antidepressants have a proven role when depression or anxiety is detected (see below) but are unlikely to have a role in cases where mood disorder has been carefully excluded (including uncomplicated personality disorders).

\section{Problem solving therapy}

Five randomised controlled trials (RCTs) have found no significant difference between problem solving therapy and usual care in the proportion of people who repeated DSH but there were benefits on depression, anxiety, and hopelessness that suggest merit. ${ }^{30}$

\section{Priority future treatment}

The advantages of the emergency card approach are that a simple, inexpensive intervention can be carried out on a large scale. The two Bristol Green Card studies found no significant reduction in the proportion of people who repeated DSH in those given an emergency card allowing emergency admission or contact with a doctor when they first came to the ED. ${ }^{31}$ However, a large randomised study of postcard invites "to drop us a note" did show a reduction in the frequency in repeat episodes in women, but not the overall proportion of self harm or any effect in men. ${ }^{32}$

Medical admission unit versus psychiatric admission Historically it has been rare for patients to be routinely admitted after DSH, but the pressures imposed by the NHS 4 hour wait in the ED are changing this policy in many hospitals. One small RCT found no significant difference in outcomes between those offered hospital admission and those given immediate discharge, but further studies are required. ${ }^{33}$ Psychiatric admission remains a valuable option when risk is high and/or serious mental health problems cannot be otherwise resolved. 


\section{Offer of follow up}

Several non-randomised studies have found that follow up reduces the subsequent rate of DSH. ${ }^{34}$ One randomised study showed long term benefit of follow up contact in those who would have not been seen otherwise. ${ }^{35}$ This will be facilitated by an adequate initial assessment.

\section{Staff trained in psychotherapy}

One RCT found equivocal evidence that intensive dialectical behaviour therapy is favourable. ${ }^{36}$ On the other hand, a relatively small RCT of psychodynamic interpersonal therapy delivered at home over 4 weeks to 199 adults reduced repetition of DSH from $28 \%$ to $9 \%$ and showed a trend for improved mood over 6 months. ${ }^{37}$

\section{Patient based self help}

This area remains almost totally unexplored. In one recent study of 480 people randomised to manual assisted cognitive behavioural therapy, 38\% attended no clinical sessions and hence had use of the booklet alone. ${ }^{38}$ This was modestly successful in reducing repeat attempts (largely confined to those without a borderline personality disorder). ${ }^{39}$

\section{General practitioners}

Of those patients seen in the ED after DSH, 50\% present to their general practitioner (GP) in the following month, mostly in the first week. ${ }^{22}{ }^{40}$ Unfortunately, a large cluster randomised trial comparing the use of GP guidelines for DSH versus usual care found no significant difference in the 12 month repetition rate for 2084 people who had attended hospital. ${ }^{41}$

\section{WHAT SHOULD I DO IF SOMEONE REFUSES TREATMENT?}

This is the area that causes most uncertainty for staff. The first step for individuals at risk who refuse treatment is to try simple persuasion. If a patient lacks the capacity to consent to treatment (whether for medical or mental health reasons) then treatment needs to be delivered in the best interests of that individual. Capacity involves being able to first comprehend and retain information, believe it, and finally weigh it in the balance to arrive at a choice. If a patient has full capacity (see British Medical Association guidelines: www.bma.org.uk/ap.nsf/Content/consenttk2 5) and is refusing treatment, then the patient's wishes for no treatment of the physical complications must be respected even though this may appear discordant with the views of the clinician. If there is any doubt concerning capacity (particularly in cases where omission of treatment would have serious consequences) then a further opinion needs to be sought from a more senior member of the medical team (specialist registrar or consultant), and if necessary from a psychiatrist. However, whether or not the patient has capacity, the Mental Health Act is an option when mental illness is suspected. To make matters more complicated, even in this case clinicians are not entitled to offer physical treatment under the Mental Health Act (although they may of course do so under common law) as the Act covers treatment for mental disorders alone. However, even when there is no formal mental disorder, somebody in the throes of an emotional crisis surrounding an attempt at suicide may not be in a position to make a fully reasoned decision. For a more detailed account, see the Royal College of Psychiatrists Council Report. ${ }^{9}$

\section{WHO SHOULD I REFER FOR FURTHER HELP?}

Although many risk factors are irreversible, certain risk factors such as poor physical health and comorbid psychiatric diagnoses are directly treatable. We suggest five factors that may justify referral for aftercare and/or referral for specialist mental health or social services: (a) chronic alcohol misuse, (b) multiple repeat attempts, (c) depression, (d) physical illness, and (e) social isolation. We also suggest mandatory referral in cases with active (ongoing) suicidal plans or intent, older people and children/adolescents.

\section{Chronic alcohol and drug problems}

Chronic alcohol and drug problems are a strong risk factor for DSH and eventual suicide. ${ }^{42}$ Current intoxication at the time of DSH may indicate an impulsive (disinhibited) attempt, but its link with chronic alcohol problems should be explored and taken seriously.

\section{Multiple repeaters}

Multiple repeaters are a problematic group for the health service; $20 \%$ of individuals who self harm repeat several times in a given year and $10 \%$ repeat at least five times. ${ }^{43}$ This group is much more likely to include individuals with persistently maladaptive ways of coping, typically in the form of an unhelpful personality traits (in these cases an integrated response and readily accessible care plan is required, possibly with involvement from psychological or psychotherapeutic services who may offer treatments such as dialectical behaviour therapy). ${ }^{44}$

\section{Mood disorder}

Rates of depression are substantial after self harm. They are particularly high in the elderly and other vulnerable groups, ${ }^{45}$ and depression is the one of the strongest risk factor for future $\mathrm{DSH}^{46}$ Suicidal thoughts and behaviour are state related in depression; resolution of the depression will almost invariably alleviate thoughts of suicide. ${ }^{47}$

\section{Medical illness}

Physical illness can be very distressing, especially when progressive or unpredictable. In the European Parasuicide Study Interview Schedule, $50 \%$ of people had a physical illness at the time of the attempt. ${ }^{48}$ Frequently, physical illness is a risk factor for complete suicide without a previously detected attempt.

\section{Isolation}

Isolation is a risk factor for suicide and particularly for self harm. ${ }^{49}$ Between 1950 and 1998 there have been rises in income inequality, divorce, amd unemployment, and declines in births and marriage. ${ }^{11}$ The majority of suicides in the elderly involve those who are single or widowed. For example, in men older than 80 years, the increase in suicide risk immediately after bereavement is 15 fold. ${ }^{18}$

\section{SHOULD ANTIDEPRESSANTS BE AVOIDED IN THOSE AT RISK OF SUICIDE?}

There has been recent media concern that selective serotonin reuptake inhibitors (SSRIs) may actually cause an emergence of suicidal thoughts or increase suicidal ideation. This appears to be manifest in short term trials but not in long term follow up. ${ }^{50}$ However, no research supports a link between SSRIs and completed suicide. ${ }^{51}$ Furthermore, there is substantial evidence that antidepressants are efficacious in treating moderate to severe depression and that patients who commit suicide tend to have been undertreated..$^{50}$ Antidepressants are therefore important in treating depression after DSH, but the clinician should be aware that SSRIs and tricyclics may temporarily worsen suicidal ideation as a result of increased activation during the early phases of treatment, and therefore close monitoring is required at the start of therapy. ${ }^{52}$

\section{WHAT CAN BE DONE TO REDUCE FUTURE DSH?}

ED staff may be well placed to prevent future suicides. One study of 219 consecutive suicides found that $39 \%$ had visited 
the ED in the previous year..$^{53}$ All patients presenting with DSH should be offered a courteous and sensitive assessment of risk, and of psychological and social need. If ED staff are to undertake psychosocial assessments it is imperative that they receive appropriate training in self harm assessment and management and risk assessment from local psychiatry services. ${ }^{9}$

Where the individual's risk is thought to be low, follow up from the GP is probably a reasonable suggestion, but communication with colleagues in primary care needs to be efficient. Prevention in primary care is also a possibility, as two thirds of patients had been in contact with their GP in the month before DSH. ${ }^{22}$ However, of these only $13.3 \%$ reported expressing suicidal thoughts, making identification of those at risk difficult. Other health strategies that may prove important are telephone helplines, easily accessible mental health crisis teams, and more global social support measures.

\section{CONCLUSIONS}

Self harm and attempted suicide is a common behaviour frequently presenting to the ED. Both the Royal College of Psychiatrists and NICE guidelines are important steps in improving the quality of service these patients receive. There are important implications for training, both for ED and specialist mental health services. Experienced mental health professionals have an important role not only in education, but also in the continuing development of services and supervision of others. Joint working between emergency medicine and psychiatry is indicated. Where available, liaison psychiatry is ideally suited to this role. The Royal Colleges of Psychiatry and Physicians, the Royal College of Nursing, and MIND, the mental health charity, have launched a collaborative to facilitate the implementation of the NICE guidelines. Hopefully, this will help to foster further the development of specialist teams and provide useful indicators of service performance.

\section{Authors' affiliations}

A J Mitchell, Department of Liaison Psychiatry, Leicester General Hospital, Leicester, UK

M Dennis, Department of Health Sciences, Psychiatry for the Elderly, Leicester General Hospital, Leicester, UK

Competing interests: none declared

\section{REFERENCES}

1 Hawton K, Fagg J, Simkin S, et al. Trends in deliberate self-harm in Oxford, 1985-1995. Implications for clinical services and the prevention of suicide. Br J Psychiatry 1997; 171:556-60.

2 Suominen K, et al. Completed suicide after a suicide attempt: a 37-year follow-up study. Am J Psychiatry 2004;161:563-4

3 Owens D, Wood C, Greenwood D, et al. Mortality and suicide after non-fatal self-poisoning: a 16-year outcome study of patients attending accident and emergency. Br J Psychiatry 2005;187:470-5.

4 Zahl DL, Hawton K. Repetition of deliberate self-harm and subsequent suicide risk: long-term follow-up study of 11583 patients. Br J Psychiatry 2004; 185:70-5.

5 Kapur N, House A, Creed F, et al. Management of deliberate self-poisoning in adults in four teaching hospitals: descriptive study. BMJ 1998;316:831-32.

6 Bennewith O, Gunnell D, Peters T, et al. Variations in the hospital management of self harm in adults in England: observational study. BMJ 2004;328: 1108-9.

7 Kapur N, House A, May C, Creed F. Service provision and outcome for deliberate self-poisoning in adults - Results from a six centre descriptive study. Soc Psychiatry Psychiatr Epidemiol 2003;38:390-5.

8 National Institute for Clinical Excellence. Self-harm. The short-term physical and psychological management and secondary prevention of self-harm in primary and secondary care. NICE: London, 2004

9 Royal College of Psychiatrists. Assessment following self-harm in adults, Council report CR 122 2004. London: Royal College of Psychiatrists. www.rcpsych.ac.uk/publications/cr/crl22.htm.

10 Dennis M, Lindesay J. Suicide in the elderly: the United Kingdom perspective. Int Psychogeriatr 1995;7:263-74.
11 Gunnell D, Middleton N, Whitley E, et al. Why are suicide rates rising in young men but falling in the elderly? a time-series analysis of trends in England and Wales 1950-1998. Soc Sci Med 2003;57:595-611.

12 Rodham K, Hawton K, Evans E. Reasons for deliberate self-harm: Comparison of self-poisoners and self-cutters in a community sample of adolescents. J Am Acad Child Adolesc Psychiatry 2004;43:80-7.

13 Hielmeland $\mathrm{H}$, Hawton $\mathrm{K}$, Nordvik $\mathrm{H}$, et al. Why people engage in parasuicide: a cross-cultural study of intentions. Suicide Life Threat Behav 2002;32:381-93.

14 Suokas J, Suominen K, Isometsa E, et al. Long-term risk factors for suicide mortality after attempted suicide-Findings of a 14-year follow-up study. Acta Psychiatr Scand 2001;104:117-21.

15 Gunnell D, Peters T, Kammerling R, et al. Relation between parasuicide, suicide, psychiatric admissions, and socio-economic deprivation. BMJ 1995;311:226-30.

16 Osvath P, Voros V, Fekete S. Life events and psychopathology in a group of suicide attempters. Psychopathology 2004;37:36-40.

17 Dennis M, Wakefield P, Molloy C, et al. Self-harm in depressed older people: a comparison of social factors, life events and symptoms. Br J Psychiatry 2005;186:538-9.

18 Erlangsen A, Jeune B, Bille-Brahe U, et al. Loss of partner and suicide risks among oldest old: a population-based register study. Age Ageing 2004;33:378-83.

19 De Vanna M, Paterniti S, Milievich C, et al. Recent life events and attempted suicide. J Affect Disord 1990;18:51-8.

20 Milnes D, Owens D, Blenkiron P. Problems reported by self-harm patients: Perception, hopelessness, and suicidal intent. J Psychosom Res 2002;53:819-22.

21 Colman I, Newman SC, Schopflocher D, et al. A multivariate study of predictors of repeat parasuicide. Acta Psychiatr Scand 2004; 109:306-312.

22 Houston K, Haw C, Townsend E, et al. General practitioner contacts with patients before and after deliberate self harm. Br J Gen Pract 2003:53:365-70.

23 Patterson W, Dohn H, Bird J, et al. Evaluation of suicidal patients: the SAD PERSONS score. Psychosomatics 1983;24:343-5.

24 Pierce DW. The predictive validation of a suicide intent scale: a five year follow-up. Br J Psychiatry 1981;139:391-6.

25 Carter Gl, Clover KA, Bryant JL, et al. Can the Edinburgh Risk of Repetition Scale predict repetition of deliberate self-poisoning in an Australian clinical setting? Suicide Life Threat Behav 2002;32:230-9.

26 Hart C, Colley R, Harrison A. Using a risk assessment matrix with mental health patients in emergency departments. Emerg Nurse 2005;12:21-8.

27 Soomro GM. Deliberate self harm (and attempted suicide). Clin Evid 2005; 13:1200-1

28 Verkes R, Van Der Mast R, Hengeveld M, et al. Reduction by paroxetine of suicidal behaviour inpatients with repeated suicide attempts but not major depression. Am J Psychiatry 1998;155:543-7.

29 Nutt DJ. Death and dependence: current controversies over the selective serotonin reuptake inhibitors. J Psychopharmacol 2003;17:355-64.

30 Townsend E, Hawton K, Altman DG, et al. The efficacy of problem-solving treatments after deliberate self-harm: meta-analysis of randomized controlled trials with respect to depression, hopelessness and improvement in problems. Psychol Med 2001;31:979-88.

31 Evans MO, Morgan HG, Hayward A, et al. Crisis telephone consultation for deliberate self-harm patients: effects on repetition. $\mathrm{Br} J$ Psychiatry 1999; 175:23-7.

32 Carter GL, Clover K, Whyte IM, et al. Postcards from the EDge project: randomised controlled trial of an intervention using postcards to reduce repetition of hospital treated deliberate self poisoning. BMJ 2005;331:805-7.

33 Waterhouse J, Platt S. General hospital admission in the management of parasuicide: a randomised controlled trial. Br J Psychiatry 1990; 156:236-42.

34 Stewart D, Gossop M, Marsden J. Reductions in non-fatal overdose after drug misuse treatment: results from the National Treatment Outcome Research Study (NTORS). J Subst Abuse Treat 2002;22:1-9.

35 Motto JA, Bostrum AG. A randomized controlled trial of postcrisis suicide prevention. Psychiatr Serv 2002;52:828-33

36 Linehan MM, Armstrong HE, Suarez A, et al. Cognitive-behavioral treatment of chronically parasuicidal borderline patients. Arch Gen Psychiatry 1991;48:1060-4.

37 Guthrie E, Kapur N, Mackway-Jones K, et al. Randomised controlled trial of brief psychological intervention after deliberate self poisoning. BMJ 2001;323:135-8.

38 Tyrer $\mathbf{P}$, Thompson S, Schmidt U, et al. Randomized controlled trial of brief cognitive behaviour therapy versus treatment as usual in recurrent deliberate self-harm: the POPMACT study. Psychol Med 2003;33:969-76.

39 Tyrer P, Tom B, Byford S, et al. Differential effects of manual assisted cognitive behavior therapy in the treatment of recurrent deliberate self-harm and personality disturbance: The POPMACT study. J Personal Disord 2004; 18:102-16.

40 Gunnell D, Bennewith O, Peters TJ, et al. Do patients who self-harm consult their general practitioner soon after hospital discharge? A cohort study. Soc Psychiatry Psychiatr Epidemiol 2002;37:599-602.

41 Bennewith O, Stocks N, Gunnell D, et al. General practice based intervention to prevent repeat episodes of deliberate self harm: cluster randomised controlled trial. BMJ 2002;324:1254.

42 Beck AT, Steer RA. Clinical predictors of eventual suicide: a 5- to 10-year prospective study of suicide attempters. J Affect Disord 1989;17:203-9.

43 Kreitman N, Casey P. The repetition of parasuicide: an epidemiological and clinical study. Br J Psychiatry 1988;153:792-800.

44 Rathus JH, Miller AL. Dialectical behavior therapy adapted for suicidal adolescents. Suicide Life Threat Behav 2002;32:146-57. 
45 Henriksson MM, Aro HM, Marttunen MJ, et al. Mental disorder and comorbidity in suicide. Am J Psychiatr 1993;150:935-40.

46 Colman I, Newman SC, Schopocher D, et al. A multivariate study of predictors of repeat parasuicide. Acta Psychiatr Scand 2004;109:306-12.

47 Sampson E, Mukheriee S, Ukoumunne OC, et al. History of deliberate selfharm and its association with mood fluctuation. $J$ Affect Disord 2004;79:223-7.

48 de Leo D, Scocco P, Marietta P, et al. Physical illness and parasuicide: Evidence from the European Parasuicide Study Interview Schedule (EPSIS/ WHO-EURO). Int J Psychiatry Med 1999:29:149-63.

49 Cooper J, Kapur N, Webb R, et al. Suicide after deliberate self-harm: A 4year cohort study. Am J Psychiatr 2005;162:297-303.
50 Isacsson G Holmgren P, Ahlner J Selective serotonin reuptake inhibitor antidepressants and the risk of suicide: a controlled forensic database study of 14857 suicides. Acta Psychiatr Scand 2005;111:286-90.

51 Fergusson D, Doucette S, Glass K, et al. Association between suicide attempts and selective serotonin reuptake inhibitors: systematic review of randomised controlled trials. BMJ 2005;330:396-9.

52 Nutt DJ. Death and dependence: current controversies over the selective serotonin reuptake inhibitors. J Psychopharmacol 2003;17:355-64.

53 Gairin I, House A, Ownes. Attendance at Accident and Emergency department in the year before suicide: a retrospective study. Br J Psychiatry 2003; 183:28-33

\section{Clinical Evidence-Call for contributors}

Clinical Evidence is a regularly updated evidence-based journal available worldwide both as a paper version and on the internet. Clinical Evidence needs to recruit a number of new contributors. Contributors are healthcare professionals or epidemiologists with experience in evidence-based medicine and the ability to write in a concise and structured way.

Areas for which we are currently seeking contributors:

- Pregnancy and childbirth

- Endocrine disorders

- Palliative care

- Tropical diseases

We are also looking for contributors for existing topics. For full details on what these topics are please visit www.clinicalevidence.com/ceweb/contribute/index. jsp

However, we are always looking for others, so do not let this list discourage you.

Being a contributor involves:

- Selecting from a validated, screened search (performed by in-house Information Specialists) epidemiologically sound studies for inclusion.

- Documenting your decisions about which studies to include on an inclusion and exclusion form, which we keep on file.

- Writing the text to a highly structured template (about 1500-3000 words), using evidence from the final studies chosen, within 8-10 weeks of receiving the literature search.

- Working with Clinical Evidence editors to ensure that the final text meets epidemiological and style standards.

- Updating the text every 12 months using any new, sound evidence that becomes available. The Clinical Evidence in-house team will conduct the searches for contributors; your task is simply to filter out high quality studies and incorporate them in the existing text.

If you would like to become a contributor for Clinical Evidence or require more information about what this involves please send your contact details and a copy of your CV, clearly stating the clinical area you are interested in, to CECommissioning@bmigroup.com.

\section{Call for peer reviewers}

Clinical Evidence also needs to recruit a number of new peer reviewers specifically with an interest in the clinical areas stated above, and also others related to general practice. Peer reviewers are healthcare professionals or epidemiologists with experience in evidence-based medicine. As a peer reviewer you would be asked for your views on the clinical relevance, validity, and accessibility of specific topics within the journal, and their usefulness to the intended audience (international generalists and healthcare professionals, possibly with limited statistical knowledge). Topics are usually 1500-3000 words in length and we would ask you to review between 2-5 topics per year. The peer review process takes place throughout the year, and out turnaround time for each review is ideally 10-14 days. If you are interested in becoming a peer reviewer for Clinical Evidence, please complete the peer review questionnaire at www. clinicalevidence.com/ceweb/contribute/peerreviewer.jsp 